\title{
DISPONIBILIDADE DE FÓSFORO EM SEIS SOLOS DO URUGUAI AFETADA PELA VARIAÇÃO TEMPORAL DAS CONDICÕES DE OXIRREDUÇÃO(1)
}

\author{
J . HER NÁNDEZ ${ }^{(2)} \&$ E. J . MEURER ${ }^{(3)}$
}

\begin{abstract}
RESUMO
Os processos de oxirredução influem na reatividade dos óxidos de ferro no solo, o que pode afetar a disponibilidade do fósforo. Com o objetivo de avaliar como estes processos interferem na disponibilidade do fósforo, realizou-se um estudo com seis solos do Uruguai sujeitos a variações temporais nas condições de oxi rredução. Amostras do horizonte A desses solos, com diferente material de origem e que ocupam posição topográfica plana e encostas baixas da paisagem, foram colocadas sob condições de alagamento por 5, 15 e 45 dias. Decorridos estes períodos de tempo, os materiais de solo foram secos durante um período de 21 dias e amostrados para análises químicas. As formas de ferro de baixa cristalinidade, extraídas pelo oxalato de amônio a pH $6\left(\mathrm{Fe}_{6}\right)$, aumentaram com o alagamento dos solos e, após a secagem, decresceram, mas ficaram, entretanto, acima dos teores iniciais. Encontrou-se uma relação significativa entre o conteúdo de carbono orgânico dos solos e a proporção de formas de ferro de baixa cristalinidade, antes e depois dos diferentes períodos de alagamento. Os teores de fósforo disponível extraídos por Bray-1 aumentaram com o alagamento e, com exceção do solo Algorta, após a secagem dos solos, di mi nuíram para valores simi lares aos iniciais. $O$ alagamento do solo e a posterior secagem determi naram o aumento das frações de ferro de maior reatividade, acarretando a adsorção de fósforo, evidenciado pelos menores teores de fósforo remanescentes na solução. Houve tendência muito definida de diminuição do fósforo na solução dos solos com o aumento dos teores de ferro em formas de alta reatividade química $\left(\mathrm{Fe}_{6}\right)$. Estes resultados indicam que, após ciclos de alagamento-secagem do solo, a adsorção do fósforo aumenta pela reação com compostos de ferro recentemente precipitados, o que resulta em menor disponi bilidade do fósforo para as plantas.
\end{abstract}

Termos de indexação: fósforo disponível, adsorção de fósforo, óxidos de ferro, alagamento-drenagem, oxidação-redução.

(1) Parte da Tese de Mestrado apresentada pelo primeiro autor ao Curso de Pós-Graduação em Ciência de Solo, Faculdade de Agronomia da Universidade Federal do Rio Grande do Sul. Porto Alegre (RS). Recebido para publicação em maio de 1999 e aprovado em novembro de 1999.

(2) Professor Adjunto da Facultad de Agronomía, Universidad de la República, CP 11900. Montevideo, Uruguay.

(3) Professor Adjunto do Departamento deSol os da Faculdade de Agronomia da Universidade Federal do Rio Grande do Sul (UFRGS). CEP 90001-970 Porto Alegre (RS). E-mail: emeurer@conex.com.br. Bolsista do CNPq. 


\title{
SUMMARY: PHOSPHORUS AVAILABILITY IN SIX URUGUAYAN SOILS AFFECTED BY ALTERNATION OF THE FLOODED-DRAINED CONDITIONS
}

\begin{abstract}
Redox processes affect the reactivity of iron oxi des and this can affect the $P$ availability in soils. To evaluate how this processes can affect phosphorus availability, this study was carried out with six U ruguayan soils, which differed in their parent material, and subjected to alternation of the flooded-drained conditions. Soil samples $(0-15 \mathrm{~cm})$ of the A horizon, wereflooded during $0,5,15$ and 45 days, drained and sampled after 21 days of air-drying. Fe extracted by ammonium oxalate at $\mathrm{pH} 6\left(\mathrm{Fe}_{6}\right)$ increased with flooding, and after re oxi dation, decreased to level s greater than the initial levels. The organic carbon content of the soils was correlated with the poorly crystalline forms of Febefore and after flooding. Phosphorus availability (Bray-1) increased during theflooding period, and, except for Algorta soil, decreased during the drying period even lower than at the initial measurements. The alternation of the flooded-drained conditions increased the iron content in high reactivity forms resulting in increasing phosphorus adsorption, as indicated by low levels of $\mathrm{P}$ in the soil sol ution. A relationship between the iron content in high reactivity forms (extracted by ammonium oxalate at $\mathrm{pH}$ 6) and the adsorption of $\mathrm{P}$ resulting from a decreased $\mathrm{P}$ solution was found. These results suggest that after flooded-drained conditions, $\mathrm{P}$ availability to plants decreases due to the absorption of $\mathrm{P}$ with recently preci pitated high reactivity forms of iron oxides.
\end{abstract}

Index terms: phosphorus availability, phosphorus adsorption, iron oxi des, fl ooding-drained soils, oxidation-reduction conditions.

\section{NTRODUÇÃO}

As variações temporais no teor de água do solo condicionadas pelo regime pluviométrico e pelas dificuldades impostas à drenagem do perfil podem provocar alterações nas condiçỗes de oxirredução do solo (Ponnamperuma, 1972). Estes processos determinam modificações na mineral ogia dos óxidos de ferro, assim como na sua capacidade de reagir com o fósforo (Savant \& Ellis J r., 1964; Willett \& Higgins, 1980; Bradley et al., 1984). A magnitude das reações dos óxidos de ferro com o fósforo depende dos seus teores totais no solo e da quantidade presente em formas de baixa cristalinidade. Períodos al ternados de oxidação-redução aumentam a fração de óxidos de ferro finamente divididos de baixa cristalinidade (Blume, 1988) eestas formas influem na disponibilidade do fósforo em condições de alagamento (Shahandeh J r. et al., 1994).

O alagamento do sol o poderesultar num aumento da disponi bilidade do fósforo, em virtude da redução do ferro e do aumento da solubilidade dos compostos com o fósforo (Aguirre\& Ríos, 1984; Roy \& DeDatta, 1985; Willett, 1989). Vel loso et al. (1993) observaram, porém, um aumento no fósforo disponível até a segunda semana do alagamento, ocorrendo, após, um decréscimo acentuado nos teores, que ficaram próximos ou inferiores aos iniciais.

O processo de reoxidação do solo diminui a disponibilidade do fósforo, em decorrência da readsorção da fração sol ubilizada, durante o período de redução, nas superfícies altamente reativas de óxidos de ferro recentemente precipitados (Patrick J r. \& Mikkelsen, 1971; Brandom \& Mikkelsen, 1979, Bradley et al, 1984). A importância destes processos que afetam a disponibilidade do fósforo para culturas, como a do arroz irrigado, por exemplo, tem sido mencionada por diferentes autores. Estudos realizados no Uruguai apresentam evidências da importância do processo, também, em sol os sujeitos a períodos curtos de anaerobiose sob pastagens (F errando \& Mercado, 1997). Entretanto, os mecanismos envolvidos nestes processos e a vel ocidade com que el es afetam a disponibilidade do fósforo não têm sido adequadamente avaliados e quantificados.

O objetivo deste trabalho foi caracterizar as variações na disponi bilidade ena adsorção do fósforo em seis sol os do U ruguai, decorrentes das alterações temporárias das formas de ferro devidas à alternância das condições de oxirredução.

\section{MATERIAL E MÉTODOS}

Foram selecionados seis solos do Uruguai, considerando os seguintes critérios: (a) posição topográfica plana e encostas baixas da paisagem, sujeitas a variações temporais nas condições de oxirredução; (b) importância na produção de 
pastagens e ou sistemas mistos de rotações pastagem e arroz e (c) diferente material de origem. No quadro 1, estão apresentadas al gumas características químicas efísicas do horizonteA desses solos. Dados complementares foram apresentados por Hernández \& Meurer (1998). Amostras coletadas na camada superficial (0-15 cm de profundidade) dos solos foram secas ao ar, moídas e peneiradas (malhas de $2 \mathrm{~mm}$ de diâmetro). Em copos plásticos, foram colocados $40,0 \mathrm{~g}$ de cada amostra dos solos, adicionando-se água até formar uma lâmina de água livre de aproximadamente $4 \mathrm{~mm}$, que foi mantida, por reposição periódica, durante os períodos em que os solos foram submetidos aos tratamentos de alagamento. Os copos foram dispostos numa bancada em laboratório, sob condições controladas de temperatura (entre 23 e $27{ }^{\circ} \mathrm{C}$ ), , eforam cobertos com um filme de polietileno preto, num anteparoa $30 \mathrm{~cm}$ de altura, para evitar o crescimento de algas, mas sem impedir a troca de gases com o ar atmosférico. Os tratamentos constituíram-se de três períodos de alagamento, 5, 15 e 45 dias, programados de forma a serem encerrados todos no mesmo dia. Após o término dos períodos de al agamento, os sol os foram secos ao ar, durante um período de 21 dias, sob temperatura ambiente.

O delineamento utilizado foi o de parcelas ao acaso, com três repetições. A unidade experimental foi composta por uma combinação entre solo, período de alagamento. Ao fim dos períodos de alagamento e ao término da secagem, foram realizadas as seguintes determinações em subamostras de cada solo: (a) formas de ferro e de fósforo extraídos por Bray-1 nofim dos períodos dealagamento; (b) fósforo extraível por Bray-1; (c) formas deferroapós 21 dias de secagem e (d) $\mathrm{pH}$ em água durante o tempo do ensaio. A coleta das amostras de solos para as determinações químicas e do $\mathrm{pH}$ foi feita na camada inferior e interna dos copos plásticos, após separação e descarte da camada superficial do solo $(4 \mathrm{~mm})$. As amostras foram secas ao ar, moídas e peneiradas (malhas de $2 \mathrm{~mm}$ de diâmetro). As determinações químicas realizadas foram as seguintes: fósforo disponível, pel o método Bray-1 (Bray \& Kurtz, 1945); carbono orgânico, pelo método de Walkley-Black (Nelson \& Sommers, 1982); pH em água, pel ométodo potenciométrico, com uma relação solo:solução de 1:2.5 (vol/vol) (Universidad, 1980); textura, pelo método de Bouyoucus (F orsythe, 1975).

Caracterização das frações de ferro - foram usados os seguintes métodos e extratores: (a) ferro total extraído pelo ditionito de sódio $\left(\mathrm{Fe}_{\mathrm{d}}\right)$, avaliado pela técnica proposta por Kilmer (1960), modificada e descrita em Cayssials \& Puentes (1974): duplicatas de $1,25 \mathrm{~g}$ de solo foram colocadas em tubos de centrífuga de $50 \mathrm{~mL}$, junto com 1,25 g de ditionito de sódio e $25 \mathrm{~mL}$ de água deionizada, e agitada durante 16 h. A suspensão foi diluída até $60 \mathrm{~mL}$ com água destilada, ajustando-se o $\mathrm{pH}$ na faixa de 3,54,0 , sendo, posteriormente, filtrada e diluída até
$100 \mathrm{~mL}$, determinando-se nela o teor de ferro; (b) ferro extraído pel o oxalato de amônio 0,2 mol L-1 a pH $3\left(\mathrm{Fe}_{3}\right)$, avaliado pela técnica ajustada por Schwertmann (1973) e descrita em Tedesco et al. (1985). As amostras dos solos foram agitadas na ausência de luz com oxalato de amônio 0,2 mol L-1 por duas horas, sendo as suspensões, posteriormente, centrifugadas, determinado-se o teor ferro na solução, e (c) ferro extraído pelo oxalato de amônio $0,2 \mathrm{~mol} \mathrm{L-1}$ a pH 6 ( $\left.\mathrm{Fe}_{6}\right)$. Esta técnica difere da anterior apenas no valor do pH da solução extratora. O ferro contido nos extratos foi determinado por espectrofotometria de absorção atômica.

Avaliação da adsorção de fósforo - em tubos de centrífuga de $50 \mathrm{~mL}$, equilibraram-se duplicatas de 2,5 g de sol o com $25 \mathrm{~mL}$ de uma solução de $\mathrm{CaCl}_{2}$ $0,01 \mathrm{~mol} \mathrm{~L}^{-1}$, contendo fósforo em quantidade equival enteà dose de $600 \mathrm{mg} \mathrm{kg}^{-1}$, adicionado como $\mathrm{Ca}\left(\mathrm{H}_{2} \mathrm{PO}_{4}\right)_{2}$. Foram adicionadas duas gotas de tolueno para inibir a flora microbiana. As amostras dos sol os foram equilibradas com a solução durante $18 \mathrm{~h}$ a $25^{\circ} \mathrm{C}$ num agitador recíproco (100 ciclos/min), centrifugadas e, posteriormente, filtradas. O teor de fósforo na solução foi determinado pelo método da redução sel etiva com cloreto de estanho, depois da adição de mol ibdato de amônio. O fósforo adsorvido pela fase sólida foi calculado por diferença entre o fósforo adicionado e aquel e quantificado na solução de equilíbrio, depois de prévia correção do fósforo inicialmente presente na solução. O índice $\mathrm{P}_{600}$ representa a percentagem do fósforo adsorvido pelo solo após a adição da dose equivalente a $600 \mathrm{mg} \mathrm{kg}^{-1}$ deP.

Nos dados obtidos, realizaram-se análises de variância e contrastes ortogonais, análises de regressão edecorrelação, utilizando os procedimentos PROC GLM, PROC REG e PROC CORR (SAS Institute, 1985).

\section{RESULTADOS E DISCUSSÃO}

Algumas características dos seis sol os estudados neste trabalho e os teores de ferro extraídos pelo ditionito de sódio $\left(\mathrm{Fe}_{\mathrm{d}}\right)$, pelo oxalato de amônio $0,2 \mathrm{~mol} \mathrm{~L}-1$ a pH $3\left(\mathrm{Fe}_{3}\right)$ e pelo oxalato de amônio $0,2 \mathrm{~mol} \mathrm{L-1}$ a $\mathrm{pH} 6\left(\mathrm{Fe}_{6}\right)$, são apresentados no quadro 1.

A fração de ferro extraída pel o oxalato de amônio $0,2 \mathrm{~mol} \mathrm{~L}^{-1}$ a $\mathrm{pH} 6\left(\mathrm{Fe}_{6}\right)$ foi avaliada no final dos diferentes períodos de alagamento e no final do período de secagem, em relação à testemunha (amostra original). Neste sentido, as análises da variância e os contrastes ortogonais foram realizados em conjunto, para cada solo, testando-se, principalmente, as hipóteses: (1) há diferença entre os teores iniciais e os correspondentes aos períodos de alagamento e secagem dos sol os, (2) há diferença 
Quadro 1. Características químicas e físicas das amostras superficiais dos seis solos estudados

\begin{tabular}{|c|c|c|c|c|c|c|c|c|}
\hline Solo & P-Bray & Argila & c.o. & pH & CTC & $F e_{d}$ & $\mathrm{Fe}_{3}$ & $\mathrm{Fe}_{6}$ \\
\hline & $\mathrm{mg} \mathrm{kg}^{-1}$ & \multicolumn{2}{|c|}{$\mathrm{g} \mathrm{kg}^{-1}$} & & $\mathrm{cmol}_{\mathrm{C}} \mathrm{kg}^{-1}$ & & $\mathrm{mg} \mathrm{kg}^{-1}$ & \\
\hline $\begin{array}{l}\text { Tipic Hapludert } \\
\text { Itapebi }\end{array}$ & 8 & 460 & 34 & 5,7 & 32 & 8.592 & 6.235 & 1.642 \\
\hline $\begin{array}{l}\text { Tipic Argiudoll } \\
\text { Algorta }\end{array}$ & 14 & 100 & 7 & 5,2 & 4 & 1.598 & 837 & 242 \\
\hline $\begin{array}{l}\text { Albic Natraqualf } \\
\text { La Charqueada }\end{array}$ & 22 & 259 & 17 & 5,4 & 12 & 2.955 & 1.732 & 792 \\
\hline $\begin{array}{l}\text { Tipic Argiudoll } \\
\text { Alférez }\end{array}$ & 5 & 179 & 18 & 5,4 & 11 & 4.490 & 2.908 & 508 \\
\hline $\begin{array}{l}\text { Tipic Argiudoll } \\
\text { Arroyo Blanco }\end{array}$ & 7 & 219 & 24 & 5,4 & 16 & 2.957 & 2.308 & 417 \\
\hline $\begin{array}{l}\text { Tipic Albaquoll } \\
\text { Kiyú }\end{array}$ & 15 & 308 & 18 & 5,4 & 15 & 5.653 & 3.633 & 758 \\
\hline
\end{tabular}

entre os teores medidos durante o alagamento com os correspondentes à amostra seca após o alagamento e (3) há diferenças nos teores de ferro de acordo com o tempo de alagamento.

Os períodos de alagamento determinaram aumentos significativos $(P<0,01)$ para a fração de ferro extraída pelo oxalato de amônio 0,2 mol L-1 a $\mathrm{pH}$ 6,0 ( $\mathrm{Fe}_{6}$ ) nas seis amostras estudadas (Quadro 2). Os solos Arroyo Blanco e Alférez apresentaram os maiores incrementos desta fração com cinco dias de alagamento (na ordem de 200 e 300\%, respectivamente), enquanto, nos demais, os aumentos foram progressivos. Os aumentos expressivos da fração $\mathrm{Fe}_{6}$ com cinco dias de al agamento nestes dois sol os foram acompanhados por um aumento mais rápido do $\mathrm{pH}$, o que estaria evidenciando maior velocidade do processo de redução (Figura 1). O aumento do $\mathrm{pH}$ em sol os ácidos após alagamento é dependente das quantidades de ferro reduzível e do teor da matéria orgânica (Yamane, 1978).

Encontraram-se correlações significativas entre o teor de carbono orgânico dos solos e os teores de ferro nas frações $\mathrm{Fe}_{6}, \mathrm{Fe}_{3}$ e para a relação $\mathrm{Fe}_{3} / \mathrm{Fe}_{d}$ (Quadro 3). Estas relações já foram observadas em trabal hos anteriores por Cayssials \& Puentes (1974) eSchwertmann \& Taylor (1989), queindicaram que altos teores e, ou, proporções de ferro sob formas de baixa cristal inidadeestão associados com altos teores de carbono orgânico e, ou, alternância de períodos de oxidação-redução, que determinam condições desfavoráveis para a cristalização dos compostos com o ferro. As correlações entre os teores de carbono orgânico e o $\mathrm{Fe}_{6}$ extraído aos 5, 15 e 45 dias de al agamento também foram significativas (Quadro 3), o que evidencia uma dependência entre a solubilização do ferro pela microbiota (sob anaerobiose) ea fonte deenergia para o metabol ismo microbiano. As correlações entre o ferro extraído pelo oxalato a pH 6 e a proporção de formas de baixa cristalinidade (relação $\mathrm{Fe}_{3} / \mathrm{Fe}_{\mathrm{d}}$ ) foram também significativas para o período de cinco dias de alagamento. Munch et al. (1978), avaliando as modificações na relação $\mathrm{Fe}_{3} / \mathrm{Fe}_{\mathrm{d}}$, resultantes da redução dos solos, encontraram correlação significativa entre o $\mathrm{Fe}^{2+}$ no final do período de redução e o $\mathrm{Fe}_{3}$ no solo antes do processo. Van Breemen (1988a,b) atribuiu a menor formação de óxi dos de ferro estáveis à redução de formas estáveis atéhidróxidos de $\mathrm{Fe}^{2+}$, que podem ser transformados rapidamente em formas metaestáveis de óxidos de $\mathrm{Fe}^{3+}$.

Após o periodo de secagem dos solos (21 dias), com exceção do solo Algorta, os teores de $\mathrm{Fe}_{6}$ diminuíram em todos os solos, independentemente do período de alagamento prévio (Quadro 2), mas ficaram, entretanto, superiores aos teores da amostra de sol o que não esteve sujeito a alagamento. Isto pode indicar que, após o período de alagamento, pode ocorrer um aumento das formas de ferro de alta reatividade. Este comportamento também foi observado por Willett \& Higgins (1978), que comprovaram que, após a drenagem (oxidação) do solo, o teor de ferro extraído pelo oxalato foi maior do que os teores iniciais quantificados antes do processo de alagamento (redução). Os óxidos de ferro recentemente oxidados são mais facilmente extraídos pelo oxalato, o que, segundos estes autores, indica uma diminuição na cristalinidade eaumento 
Quadro 2. Aumentos percentuais do ferro extraído pelo oxalato de amônio $0,2 \mathrm{~mol} \mathrm{~L}^{-1}$ a pH 6 ( $\left.\mathrm{Fe}_{6}\right)$ no final de cada período de alagamento e após 21 dias de secos ao ar, em temperatura ambiente, em relação ao teor inicial da amostra original (sem alagar)

\begin{tabular}{|c|c|c|c|c|c|c|}
\hline Tratamento Solo & $\begin{array}{c}\text { Tipic } \\
\text { Haplubert } \\
\text { Itapebi }\end{array}$ & $\begin{array}{c}\text { Tipic } \\
\text { Argiudoll } \\
\text { Algorta }\end{array}$ & $\begin{array}{c}\text { Albic } \\
\text { Natraqualf La } \\
\text { Charqueada }\end{array}$ & $\begin{array}{c}\text { Tipic } \\
\text { Argiudoll } \\
\text { Alférez }\end{array}$ & $\begin{array}{c}\text { Tipic } \\
\text { Argiudoll } \\
\text { Arroyo Blanco }\end{array}$ & $\begin{array}{c}\text { Tipic } \\
\text { Albaquoll } \\
\text { Kiyú }\end{array}$ \\
\hline 5 dias de alagamento & 12 & 8 & 74 & 231 & 304 & 74 \\
\hline após secagem de 21 dias & 1 & 55 & 44 & 149 & 166 & 44 \\
\hline 10 dias de alagamento & 50 & 42 & 84 & 323 & 340 & 122 \\
\hline após secagem de 21 dias & 11 & 93 & 38 & 174 & 192 & 82 \\
\hline 15 dias de alagamento & 45 & 104 & 99 & 331 & 365 & 183 \\
\hline após secagem de 21 dias & 29 & 114 & 42 & 190 & 198 & 108 \\
\hline
\end{tabular}

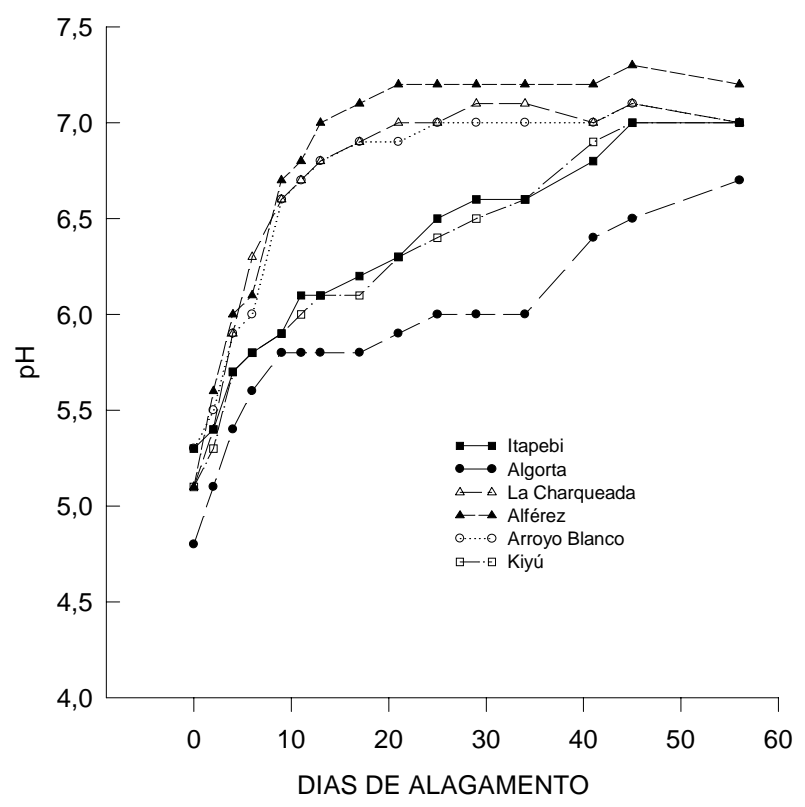

Figura 1. Evolução do pH em água dos seis solos durante $\mathrm{o}$ alagamento.

da sua reatividade. O comportamento diferenciado do solo Algorta, que apresentou as menores mudanças na fração $\mathrm{Fe}_{6}$ e no $\mathrm{pH}$, pode estar relacionado com os seus menores teores de ferro nas diferentes frações, além do baixo teor de matéria orgânica.

Fósforo disponível - os teores de fósforo extraído pelo Bray-1, após os diferentes períodos de alagamento, para os seis solos, são apresentados na figura 2. Com exceção do solo Algorta, nos demais sol os, os teores de fósforo aumentaram significativamente $(P<0,01)$ com o tempo de alagamento em
Quadro 3. Coeficientes de correlação e sua probabilidade de significância para as relações entre o teor de carbono orgânico dos solos e da razão $\mathrm{Fe}_{3} / \mathrm{Fe}_{\mathrm{d}}\left(\mathrm{Fe}_{\mathrm{d}}=\right.$ ferro extraído por ditionito) e os teores de ferro extraídos por oxalato de amônio a pH $3\left(\mathrm{Fe}_{3}\right)$, a pH $6\left(\mathrm{Fe}_{6}\right)$, para as amostras dos solos submetidas a $5,15 \mathrm{e}$ 45 dias de alagamento

\begin{tabular}{|c|c|c|c|c|}
\hline \multirow{2}{*}{ Variável } & \multicolumn{2}{|c|}{ C orgânico } & \multicolumn{2}{|c|}{ Razão $\mathrm{Fe}_{3} / \mathrm{Fe}_{\mathrm{d}}$} \\
\hline & $r$ & Probabilidade & $r$ & Probabilidade \\
\hline $\mathrm{Fe}_{3}$ & 0,756 & 0,024 & & \\
\hline $\mathrm{Fe}_{6}$ & 0,672 & 0,046 & & \\
\hline $\mathrm{Fe}_{3} / \mathrm{Fe}_{\mathrm{d}}$ & 0,710 & 0,035 & & \\
\hline $\mathrm{Fe}_{6}$ (5 dias) & 0,743 & 0,027 & 0,687 & 0,042 \\
\hline $\mathrm{Fe}_{6}$ (15 dias) & 0,788 & 0,018 & 0,628 & 0,060 \\
\hline $\mathrm{Fe}_{\mathrm{b}}$ (45 dias) & 0,655 & 0,048 & 0,573 & 0,082 \\
\hline
\end{tabular}

relaçãoà testemunha (amostra original), tendo o solo La Charqueada apresentado os maiores acréscimos com o alagamento. Nos demais solos, os aumentos dos teores do fósforo foram mais dependentes do tempo de al agamento. Este comportamento pode ser relacionado com a proporção de ferro em formas de alta reatividade no solo. No solo La Charqueada, a quarta parte do ferro extraído pelo ditionito $\left(\mathrm{Fe}_{\mathrm{d}}\right)$ na amostra não submetida ao alagamento encontrava-se em compostos de al ta reatividade química extraídos pel o oxalato de amônio a pH 6 . 0 solo Algorta, ao contrário, apresentou menor proporção de $\mathrm{Fe}_{6}$, além de menores teores absol utos, e as mudanças no teor do fósforo disponível não 
foram significativas estatisticamente. No solo I tapebi, as mudanças na disponibilidade do fósforo aconteceram principalmente nos maiores períodos de alagamento. Esses resultados concordam com os obtidos por diversos autores (Savant \& Ellis) r., 1964; Roy \& De Datta, 1985; Willett, 1989; Velloso et al., 1993). De Datta et al. (1966) observaram que o alagamento do solo por longos períodos aumentava o teor de fósforo disponível de 2,5 até 15 vezes em relação ao teor em solo não alagado. Eles interpretaram este aumento mais pela redução dos compostos de ferro que pelo aumento no $\mathrm{pH}$, como foi referenciado por outros autores (Patrick J r. \& Mikkelsen, 1971).

Após o período de secagem dos sol os (21 dias), os teores de fósforo extraível com Bray-1 diminuíram significativamente $(P<0,01)$ em todos os sol os, com exceção do solo Algorta (Figura 3), em relação aos teores extraídos ao final dos períodos de alagamento (F igura 2), ficando com valores não estatisticamente diferentes dos quantificados nas amostras originais não submetidas ao alagamento. E sse comportamento pode indicar que, independentemente do período que estiveram submetidos ao alagamento, os teores do fósforo extraído dos solos, após a secagem, voltam aos seus níveis iniciais ou próximos del es. A redução acentuada do fósforo extraível após a secagem dos solos pode ser interpretada como uma readsorção do fósforo nas superfícies deal ta reatividadequímica dos óxidos de ferro recentemente precipitados após o período de alagamento.

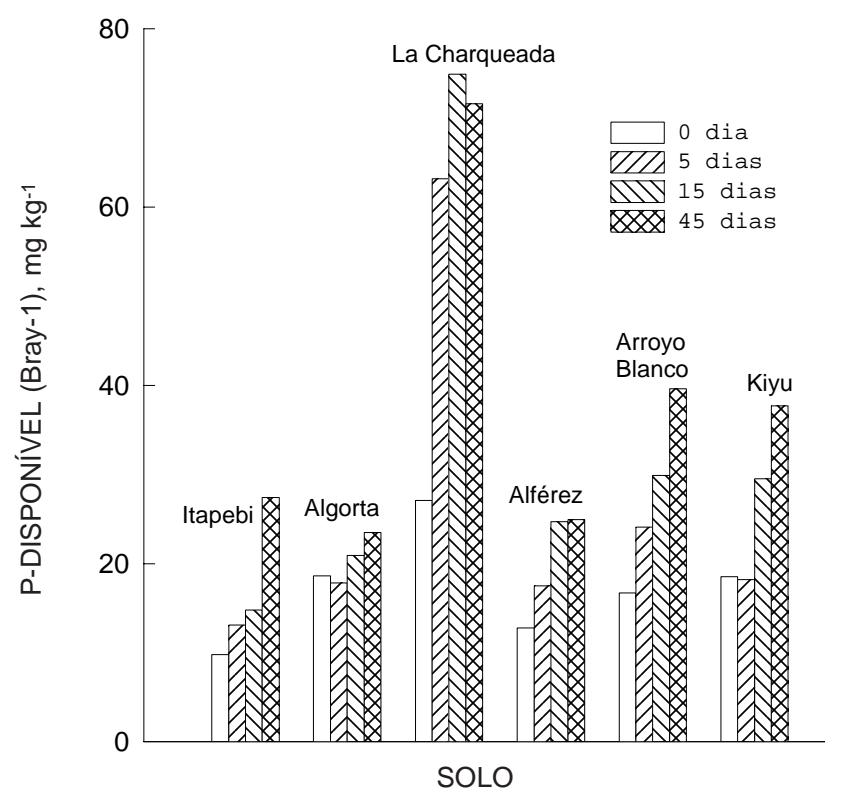

Figura 2. Teores de fósforo disponível por Bray-1 nos seis solos, nas amostras originais e após serem submetidas aos períodos de alagamento.

\section{Adsorção de fósforo}

Após o período de secagem (21 dias), col etaramse amostras dos solos, das amostras originais e das que foram submetidas aos três períodos de alagamento, para estudar a adsorção de fósforo. $\mathrm{Na}$ figura 4, vêem-se os teores de fósforo na solução dessas amostras após equilíbrio com uma solução com fósforo na concentração equival ente à dose de $600 \mathrm{mg} \mathrm{kg}^{-1}$ de P. Em todos os solos, os teores de fósforo na solução foram significativamente inferiores $(P<0,01)$ aos da amostra original. I sto indica que, após os períodos de alagamento e de secagem dos sol os, ocorreu mai or adsorção do fósforo, evidenciado pelos menores teores de fósforo remanescentes na solução de equilíbrio. Atribui-se a maior adsorção do fósforo ao aumento das formas de ferro de alta reatividade, como visto e discutido anteriormente (Quadro 2). As mudanças mais acentuadas aconteceram nos sol os La Charqueada, Alférez, Arroyo Blanco e Kiyú, o que pode estar relacionado com os altos teores de ferro extraído pelo oxalato de amônio a pH 6 durante o período de alagamento.

Por outrolado, cinco dias de alagamento tiveram um efeito similar na adsorção de fósfor o que períodos mais longos, o que está associado com os aumentos nos níveis de $\mathrm{Fe}_{6}$ nesse período. O comportamento observado evidencia a importância do aumento das superfícies de óxidos de ferro altamente reativas no processo deadsorção de fósforo pel os sol os. Segundo

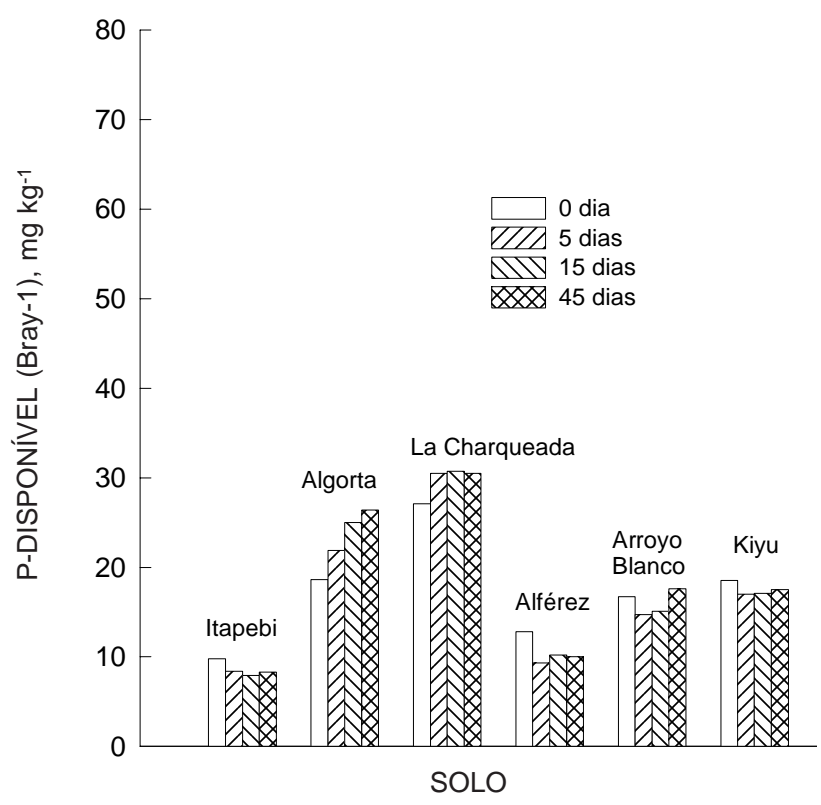

Figura 3. Teores de fósforo disponível por Bray-1 nos seis solos, nas amostras originais e após serem submetidas aos períodos de alagamento e de secagem por 21 dias. 
Sah et al. (1989), períodos tão curtos como dois a quatro dias de alagamento podem causar um aumento da adsorção de fósforo, dependendo da

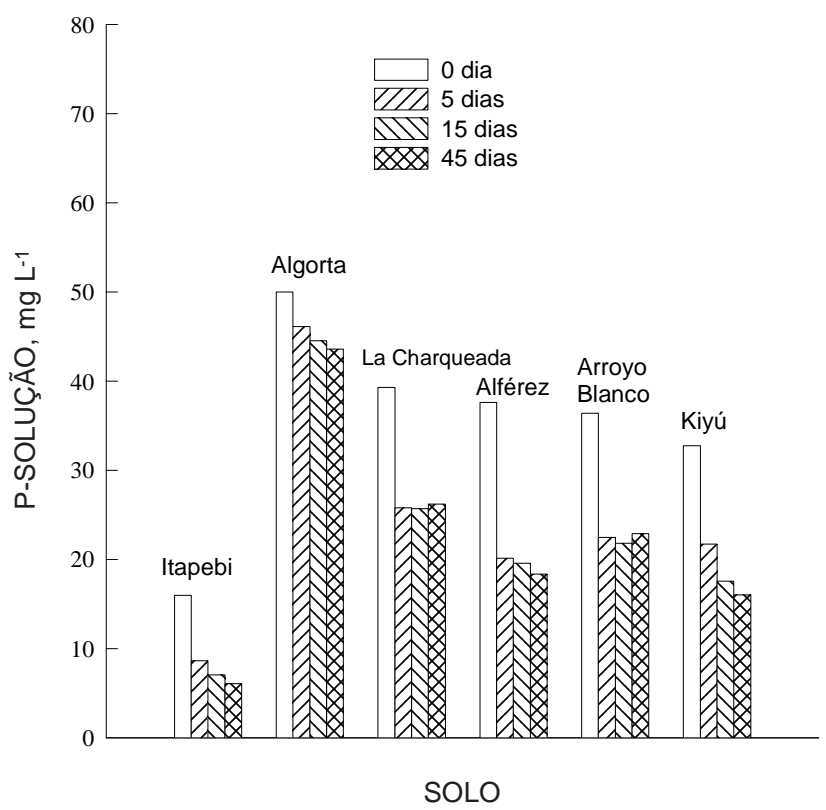

Figura 4. Teores de $P$ na solução dos seis solos, após a adição de uma quantidade equivalente a dose de $600 \mathrm{mg} \mathrm{kg}^{-1} \mathrm{de} P$ às amostras originais e às que foram submetidas aos períodos de alagamento e de secagem por 21 dias.

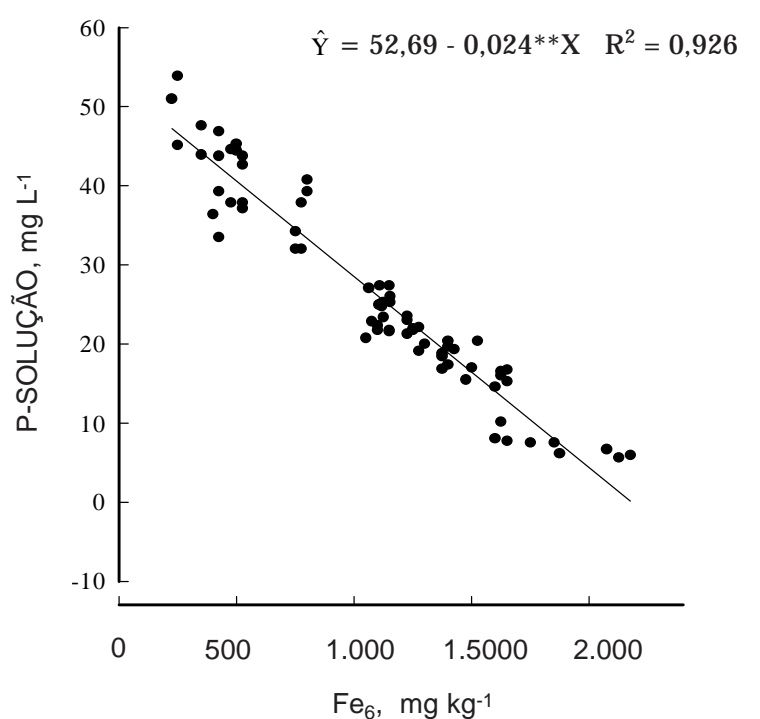

Figura 5. Relação entre os teores de $P$ na solução, após a adição de uma quantidade equivalente à dose de $600 \mathrm{mg} \mathrm{kg}^{-1}$ de $\mathrm{P}$ e os teores de ferro extraídos por oxalato de amônio $0,2 \mathrm{~mol} \mathrm{~L}^{-1}$, nas amostras dos seis solos, originais e após submetidas aos períodos de alagamento e de secagem por 21 dias. temperatura, do teor e qualidade da matéria orgânica e da natureza do solo.

Encontrou-sesignificativa relação entre os teores de fósforo na solução, após equilíbrio das amostras com a solução que continha fósforo na concentração equivalente à dose de $600 \mathrm{mg} \mathrm{kg}^{-1}$ de $\mathrm{P}$, e os teores de ferro na fração $\mathrm{Fe}_{6}$ (Figura 5). Após os períodos de alagamento e o subseqüente período de secagem dos solos, verificou-se uma tendência muito definida de diminuição dos teores do fósforo na solução com o aumento dos teores de ferro em formas de alta reatividade química $\left(\mathrm{Fe}_{6}\right)$. Isto corrobora que a adsorção do fósforo aumenta com o ciclo de alagamento e secagem do solo decorrente do aumento das frações de ferro de maior reatividade (Quadro 2). Tal comportamento pode indicar que o fósforo suprido ao solo após um período de alagamento prévio vai reagir com os compostos de fer ro recentemente precipitados, de al ta reatividade química, diminuindo a sua disponibilidade e conseqüente eficiência de utilização pelas plantas.

\section{CONCLUSÕES}

1. As formas de ferro de baixa cristalinidade $\left(\mathrm{Fe}_{6}\right)$ aumentaram com o alagamento dos solos e, após a secagem, decresceram; entretanto, ficaramacima dos níveis iniciais.

2. Os teores de fósforo disponível, determinados pel o extrator Bray-1, aumentaram com o al agamento e, com exceção do solo Algorta, diminuíram para valores similares aos iniciais após a secagem dos solos.

3. O alagamento dos sol os e a posterior secagem determinaram um aumento significativo da adsorção do fósforo do sol o devido ao aumento das frações de ferro de maior reatividade. Houve uma tendência muito definida de diminuição do fósforo na solução dos solos com o aumento dos teores de ferro em formas de alta reatividade química $\left(\mathrm{Fe}_{6}\right)$.

4. Períodos curtos de alagamento, seguidos de secagem, foram suficientes para determinar uma diminuição na disponibilidade do fósforo, pela maior adsorção e redução de seus teores na solução.

\section{LITE RATURA CITADA}

AGUIRRE, E. \& RIOS, M. Relevamiento nutricional y de otras variables de producción en el área arrocera deTacuarembó. Montevideo, Facultad de Agronomía, 1984. 249p. (Tese Engenheiro Agrônomo)

BRADLEY, J .; VIMPANY, I. \& NICHOLLS, P.J . Effects of water logging and subsequent drainage of a pasture soil on phosphate sorption, extractable phosphate and oxalateextractable iron. Aust. J . Soil Res., 22:455-461, 1984. 
BRANDON, D.M. \& MIKKELSEN, D.S. Phosphorus transformations in alternately flooded California soils: I. Cause of plant phosphorus deficiency in rice rotation crops and correctional methods. Soil Sci. Soc. Am. J ., 43:989-994, 1979.

BRAY, R.H. \& KURTZ, L.T. Determination of total, organic and available forms of phosphorus in soils. Soil Sci., 59:39-45, 1945.

BRUME, H.P. The fate of iron during soil formation in humidtemperate environments. In: STUCKI, J.W.; GOODMAN, B.A. \& SCHWERTMANN, U., eds. Iron in soils and clay minerals. Dordrecht, D. Reidel Publishing Company, 1988. p.749-777.

CAYSSIALS, R. \& PUENTES, R. Determinación y fraccionamiento de hierroy aluminiolibreen al gunos suel os del U ruguay. Montevideo, Facultad deAgronomía, 1974. 88p. (Tese - Engenheiro-Agrônomo)

DE DATTA, S.K.; MOOMAW, J .C.; RACHO, V.V. \& SIMSIMAN, J.V. Phosphorus supplying capacity of lowland rice soils. Soil Sci. Soc. Am. Proc., 30:613-617, 1966.

FERRANDO, M. \& MERCADO, G. Efecto de períodos alternados de exceso de agua y secado de los suel os en la disponibilidad de fósforo. Montevideo, Facultad de Agronomía, 1997. 92p. (Tese - Engenheiro-Agrônomo)

FORSYTHE, W. Análisis de la distribución del tamaño de las particulas. In: FORSYTHE, W. Física de suelos; manual de laboratorio. Costa Rica, IICA, 1975. p.46-68.

HERNANDEZ, J . \& MEURER, E.J . Asorção de fósforo e sua relação com formas de ferro em dez solos do Uruguai. R. Bras. Ci. Solo, 22:223-230, 1998.

KILMER, V. The estimation of free iron oxides in soils. Soil Sci. Soc. Am. Proc., 24:420-421, 1960.

MUNCH, J.C.; HILLEBRAND, T.H. \& OTTOW, J.C.G. Transformations in the $\mathrm{Feo} / \mathrm{Fed}$ ratio of pedogenic iron oxides affected by iron-reducing bacteria. Can. J. Soil Sci., 58:475-486, 1978.

NELSON, D.W. \& SOMMERS, L.E. Total carbon, organic carbon and organic matter. In: PAGE, A.L., ed. Methods of soil analysis. Part 2. Chemical and microbiological properties. Madison, American Society of Agronomy, 1982. p.539-579 (Agronomy Monograph, 9)

PATRICK J r., W.H. \& MIKKELSEN, D.S. Plant nutrient behavior in flooded soil. In: OLSON, R.A.; ARMY, T.J .; HANWAY, J .J . \& KILMER, V.J ., eds. Fertilizer technology and use. 2.ed. Madison, Soil Science Society of America, 1971. p.187-215.

PONNAMPERUMA, F.N. Thechemistry of submerged soils. Adv. Agron., 24:29-96, 1972.

ROY, A.C. \& DE DATTA, S.K. Phosphate sorption isotherms for evaluating phosphorus requirement of wetland rice soils. Plant Soil, 86:185-196, 1985.
SAH, R.N.; MIKKELSEN, D.S. \& HAFEZ, A.A. Phosphorus behavior in flooded-drained soils. I. Effects on phosphorus sorption. Soil Sci. Soc. Am. J ., 53:1718-1722, 1989.

SAS Institute, Inc. SAS User's Guide: Statistics. Cary, 1985.

SAVANT, N.K.\& ELLIS J r., R.L. Changes in redox potential and phosphorus availability in submerged soils. Soil Sci., 98:388394, 1964.

SHAHANDEH, H., HOSSNER, L.R. \& TURNER, F.T. Phosphorus relantionships in flooded rice soils with low extractable phosphorus. Soil Sci. Soc. Am. J ., 58:1184-1189, 1994.

SCHWERTMANN, U.\& TAYLOR, R.M. I ron oxides. In: DIXON, J .B. \& WEED, S.B., eds. Minerals in soil environments. 2.ed. Madison, Soil Science Society of Amercia, 1989. p.379-438.

SCHWERTMANN, U. Use of oxalate for Fe extraction from soils. Can. J . Soil Sci., 53:244-246, 1973

TEDESCO, M.J .; GIANELLO, C.; BISSANI, C.A.; BOHNEN, H. \& VOLKWEISS, S.J. Análises de solo, plantas e outros materiais. 2.ed. Porto Alegre, Universidade Federal do Rio Grande do Sul, 1985. 174p. (Boletim Técnico, 5)

UNIVERSIDAD DE LA REPUBLICA DO URUGUAY. FACULTAD DE AGRONOMIA. Pautas de trabajo en el laboratorio de suel os. Montevideo, 1980. 21p.

van BREEMEN, N. Effects of seasonal redox processes involving iron on the chemistry of periodically reduced soils. In: STUCKI, J .W.; GOODMAN, B.A. \& SCHWERTMANN, U., eds. Iron in soils and clay minerals. Dordrecht, D. Reidel Publishing Company, 1988a. p.797-809.

van BREEMEN, N. Long-term chemical, mineralogical and morphological effects of iron-redox processes in periodically flooded soils. In: STUCKI, J.W.; GOODMAN, B.A \& SCHWERTMANN, U., eds. I ron in soils and clay minerals. Dordrecht, D. Reidel Publishing Company, 1988b p.811-823.

VELLOSO, A.C.X.; DE OLIVEIRA, C. \& LEAL, J.R. Processos redox em glei húmico do Estado do Rio de J aneiro: III. Variaçao das concentraçoes de Fe (II) e fosfato. R. Bras. Ci. Solo, 17:27-33, 1993.

WILLETT, I.R. \& HIGGINS, M.L. Phosphatesorption by reduced and reoxidized ricesoils. Aust. J . Soil Res., 16:319-326, 1978.

WILLETT, I.R. \& HIGGINS, M.L. Phosphate sorption and extractable iron in soils during irrigated rice-upland crop rotations. Aust. J . Exp. Agric. Anim. Husb., 20:346-353, 1980.

WI LLETT, I.R. Causes and prediction of changes in extractable phosphorus during flooding. Aust. J. Soil Res., 27:45-54, 1989.

YAMANE, I. Electrochemical changes in rice soils. In: INTERNATIONAL RICE RESEARCH INSTITUTE. Soils and rice. Los Baños, 1978. p.381-398. 